This item was submitted to Loughborough's Research Repository by the author.

Items in Figshare are protected by copyright, with all rights reserved, unless otherwise indicated.

\title{
Drainage behavior of sports pitches-A case study review
}

\section{PLEASE CITE THE PUBLISHED VERSION}

https://doi.org/10.2134/itsrj2016.06.0450

\section{PUBLISHER}

(C) International Turfgrass Society and ACSESS

\section{VERSION}

AM (Accepted Manuscript)

\section{PUBLISHER STATEMENT}

This work is made available according to the conditions of the Creative Commons Attribution-NonCommercialNoDerivatives 4.0 International (CC BY-NC-ND 4.0) licence. Full details of this licence are available at: https://creativecommons.org/licenses/by-nc-nd/4.0/

\section{LICENCE}

CC BY-NC-ND 4.0

\section{REPOSITORY RECORD}

Fleming, Paul, Matthew W. Frost, Murray R. Simpson, R. Everett, and R.J. Gibbs. 2019. "Drainage Behavior of Sports Pitches-a Case Study Review". figshare. https://hdl.handle.net/2134/32278. 


\title{
Drainage behaviour of sports pitches - a case study review
}

\author{
P.R. Fleming1, M.W. Frost ${ }^{1}$, M. Simpson¹, R. Everett ${ }^{2}$ and R.J. Gibbs ${ }^{2}$ a \\ 1 Loughborough University, School of Civil and Building Engineering, Loughborough LE11 3TU, UK; 2 Sports Turf \\ Research Institute, St Ives Estate, Bingley BD16 1AU, UK.
}

\begin{abstract}
The drainage behaviour of sports pitches has traditionally been designed from experience with hydraulic performance rarely measured in detail. Within the wider industry and regulatory bodies there is a perception that storm water and increased drainage rates from sports pitches contribute to local flood risk.

Empirical observations have suggested that in reality pitch drainage systems may discharge water at low volumes and rates and there is often limited surface run-off. Furthermore it appears that lack of technical guidance on sport pitch drainage may have led to misunderstanding their drainage behaviour and possible benefits they could bring to water management as opposed to perceived dis-benefits.

This paper summarises selected results of a case study which included field measurements of weather and discharge behaviour on a range of natural turf sports pitches in England.

The findings from this study indicate that natural turf sports pitches can provide resistance to flow and hence advantageous attenuation of rainfall and storm water. Additionally they can store large volumes of water within the pervious materials used in their design. The study has confirmed that sport pitches demonstrate the key functions that are reflected in the design requirements of Sustainable Urban Drainage Systems (SuDs) such as pervious pavements providing source control of surface rain water.
\end{abstract}

Keywords: drainage, attenuation, storm water, SuDs, natural turf sports pitch, flood risk

\section{INTRODUCTION}

The occurrence and severity of flooding is increasing annually; emerging research reinforces the need for improved drainage infrastructure to reduce flood risk (Barros, 2014). Government and planning authorities in the UK are imposing restrictions on surface water discharges from new developments into existing drainage infrastructure and watercourses.

New sports facilities in the UK have been subject to such drainage restrictions. In particular, the large coverage of sports surfaces (typically $>7500 \mathrm{~m}^{2}$ for a full-sized sports pitch) has resulted in the anticipation of large volumes of rainwater entering local watercourses in a potentially unconstrained way. To manage these perceived large volume yields of storm-water, facilities may invest in large (separate) attenuation tanks designed to store the storm water for controlled release into the local drainage network without making any use of the properties of the pitch itself. These systems are effective at limiting the impact of drainage discharge, but can represent a significant additional cost to a project budget.

It was considered possible to address the above issue through better understanding of the hydraulic properties of sports pitch constructions, on the basis that their pervious and porous designs lend themselves to an intrinsic storage and attenuation as found in Sustainable Urban Drainage Systems (SuDs) systems such as green roofs or permeable car parks. For example,

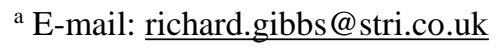


Adams and Gibbs (1994) estimated that a typical sand/gravel slit drainage system may be able to store the equivalent of approximately 4 or $5 \mathrm{~mm}$ of rainfall in the permeable backfill material of the drains.

SuDs form part of the latest building regulations in the UK and aim to capture, store and attenuate storm water at source in most cases returning it to the ground. If SuDs principles can be integrated more effectively within sports pitch drainage design, many opportunities exist for the industry to enhance current construction and regulatory practice.

The study was carried out in collaboration with industry, and funded a three year PhD programme at Loughborough University. The aim of the research study was to measure and understand the hydraulic performance of natural and artificial turf sport pitches. This paper reports on the component of the study that investigated the drainage performance of existing natural sports pitch drainage systems at selected field locations.

\section{OVERVIEW OF URBAN DRAINAGE IN THE UK}

Growth in urban areas has led to an increase in impervious surfaces such as roads, car parks and roofs (Mansell, 2003). These surfaces act as barriers that limit the natural infiltration of rainfall into the ground where it lands. The resulting impact is an increase in surface water volume conveyed through storm water drains to a receiving watercourse. One impact of urbanisation has been a reduction in the infiltration capacity of the land and an increase in the speed at which run-off reaches local watercourses. The 'lag time', i.e. the time between the peak rainfall intensity and peak discharge, can be reduced by a factor of eight (Mansell, 2003). This reduction can greatly increase the risk of flooding locally. In contrast, allowing infiltration of storm water into the ground ensures the water flow routes become more convoluted which in turn reduces the rate and volume of run-off from an area. Such an approach forms the basis for modern urban sustainable drainage practices (SuDs).

SuDs is the general term for dynamic flood water management systems, by utilising and enhancing the environment's natural ability to attenuate surface water flooding as close to the source as possible - often termed source control.

Modern permeable paving is an example of integrating SuDs into design. Rainwater infiltrates directly into the ground below the paving blocks and the foundation offers some degree of storage (and filtration) in an open textured granular material. For more storage capacity, voided structures can be used such as geo-cellular boxes, over-sized pipes or tanks (WoodsBallard et al., 2007).

Key legislative drivers for SuDs originate at European level, for example from the Water Framework Directive (WFD) (2000/60/EC) that aims to safeguard the environment for future generations and achieve a good ecological status in all watercourses. UK planning and policy guidance includes Planning Policy Statement 25 (2010) for urban developments which promote SuDs philosophy. SuDs design and construction guidance is set out in the SuDs Manual (WoodsBallard et al., 2007).

The key SuDs design principle is to provide sufficient storage, and usually some form of outflow control, to mimic that of antecedent conditions prior to development and to prevent runoff from entering watercourses at a rate greater than the 'greenfield' conditions. Predicted outflow is calculated using various methods and is normally imposed as a condition of planning (Woods-Ballard et al., 2007). Depending on the design life and risk, the storage requirement is estimated from the predicted rainfall data for the area in question for a specific storm duration and return period, usually using the HR Wallingford Procedure (1981) or recent adaptations of that approach (Woods-Ballard et al., 2007). Normal practice is to add a percentage surplus onto design storm intensities to account for the influence of climate change (e.g. 30\%).

There is no standard value for a permitted discharge/greenfield run-off rate; such values are agreed during the planning application process. Nevertheless, anecdotal evidence suggests that values of around 5-7 $\mathrm{L} \mathrm{s}^{-1} \mathrm{ha}^{-1}$ are typical. 
Flood risk and drainage design are based on statistical probability of a rainfall event occurring based on past records. Hence there is a probability that the capacity of a drainage system will be exceeded during its design life. Thus a balance must be achieved between the cost of the drainage system and the risk of a flood exceeding the system design capacity. In general the longer the return period selected for design, the lower the probability of exceeding the capacity but the greater the potential impact of flooding.

The design return period is again normally specified as a planning constraint based on the potential risk and impact of any flooding or run-off. If the flooding is likely to affect property, a higher design return period will be specified, compared to where there is a minimal risk (WoodsBallard et al., 2007). The conceptual framework for effective storage and attenuation in a SuDs system is shown in Figure 1.

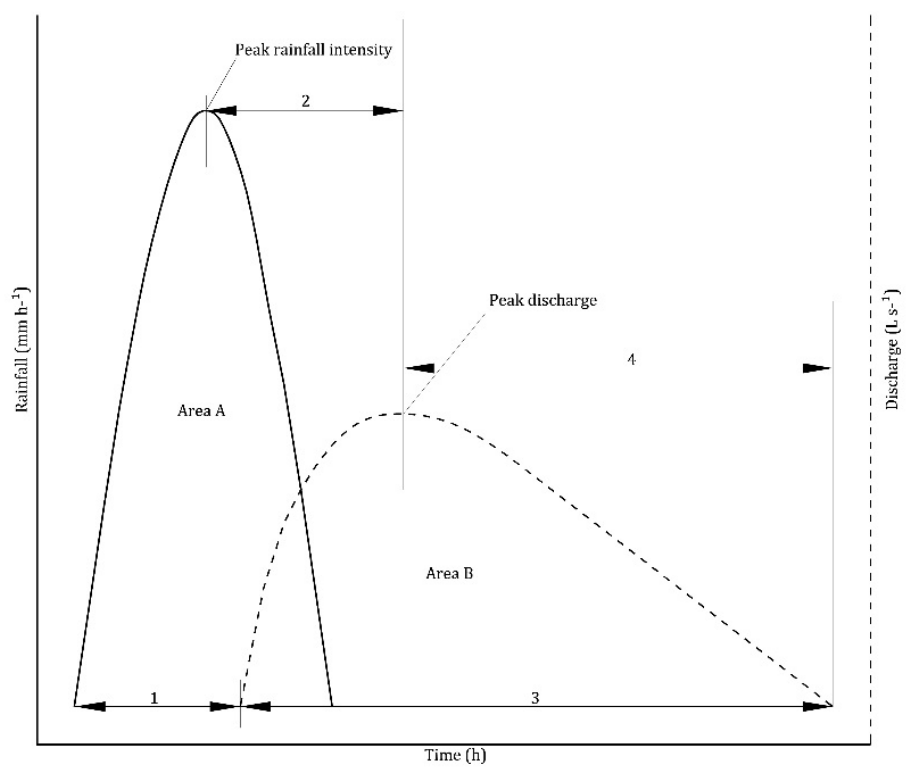

Figure 1. Conceptual model of a drainage system, showing the outflow hydrograph with the hyetograph of rainfall intensity $\left(\mathrm{mm} \mathrm{h}^{-1}\right)$ plotted against time.

In addition to the key input parameters of peak rainfall intensity and duration, and drainage system discharge rate, additional parameters to describe the system behaviour include:

- The time taken from start of rainfall to the point when a first response is recorded at the drainage outfall (1. Time of concentration).

- The duration between the highest intensity rainfall and the corresponding peak in discharge (2. Lag time).

- The total length of time that water drains or is yielded from the pitch (3. Discharge duration).

- The time taken for the rainfall event to dissipate and drainage discharge to reach baseline conditions (4. Time to base flow).

From Figure 1 it can be observed that the total volume of rainfall is shown by Area A, with the total volume discharged at the outfall being Area B. An effective attenuation and storage system will provide resistance to water flow such that there is a time interval between rainfall and discharge flow, and a time lag between peak rainfall intensity (inflow over time) and the highest discharge rate. The reduction in peak discharge, relative to the peak rainfall intensity is termed the 'attenuation' of the system, a ratio expressed as a percentage. 
A large attenuation is positive in reducing flood risk downstream; however, it is also important to consider the actual discharge flow rate. There is a consequence of high attenuation in the need for effective storage of the volume of water being 'held' in the system. To attenuate very high storm intensities to some appropriate level clearly requires adequate storage within the system or the water level will back up and cause ponding and uncontrolled surface water runoff at the facility being drained. The volume of storage required is a balance of the storm return period, the outflow constraint and the design storm that requires most attenuation. These parameters vary depending on the specific circumstances. The design of attenuation and storage is an iterative calculation and can be laborious by hand. A number of proprietary software systems have been developed with various add-on packages and graphical interfaces for design procedures. These require inputs of typical design storms, locations and return periods and an outflow hydrograph based on a design flow control as imposed by planning constraints. These design constraints are then run through mathematical models of the designed drainage and storage system making allowance for infiltration rates, time of concentration and time of flow in pipe networks, to calculate a design storage volume required to attenuate flows (Woods-Ballard et al., 2007).

While there are currently no packages with specific sports pitch modules, designs have been undertaken using an approximation of the systems using either green roof or permeable pavement modelling packages where the input parameters and performance constraints of the drainage system are observed to be similar.

\section{MATERIALS AND METHODS}

A screening process was used to select sites suitable for drainage monitoring including requirements for full ground information, as-built drainage plans, single outfalls and suitable monitoring chambers. Of an initial 28 sites investigated, two were identified for monitoring for the natural turf component of this project. The first site at Bicester Sports Village in North Oxfordshire consisted of two sports pitches of $17,160 \mathrm{~m}^{2}$ in total area. Both pitches drained to a single outfall. Immediately upstream of this outfall a chamber was installed to house a 'flume' and data logger for monitoring drainage outflow, along with a neighbouring weather station to record rainfall intensity. The flume capacity for full bore flow was approximately $12 \mathrm{~L} \mathrm{~s}^{-1}$. The second site at Merchant Taylors' School in Northwood, Middlesex also consisted of two pitches 117,735 $\mathrm{m}^{2}$ ) plus an athletics track giving a total area $25,000 \mathrm{~m}^{2}$, again with drainage to a single outfall.

The key drainage design elements of the natural sports pitches evaluated at both sites are shown in Figure 2. Injected sand slit drains (sand bands) intersected lateral pipe drains, which in turn delivered drainage water into a main collector drain. In addition, the natural turf pitches were each constructed with a 1:100 cross fall to aid surface flow. Preliminary site measurements using soakaway tests showed little to no subsoil drainage capacity.

The above type of injected slit drainage design was chosen because it was representative of 'local authority' or 'community/school level' pitches. For each site, drainage outflow and rainfall intensity monitoring took place between late 2011 and 2014. Results are summarised here over seven 'notable' rainfall events that occurred during that period at the two sites. More detailed analysis is also presented of both a high yield and a low yield rainfall event and associated drainage outflows for the monitored natural turf pitches at Bicester Sports Village. During the assessment and selection of rainfall events, an antecedent dry period of at least 20 hours was targeted where antecedent rainfall is the duration in hours of zero rainfall leading up to the rainfall event in question. This target was selected as preliminary field trials identified that the pitches took on average less than 20 hours to drain down to zero discharge. This approach gave an indication of how isolated the selected rainfall event was from antecedent weather.

\section{RESULTS}

Table 1 summarises behaviour trends observed from the seven 'notable' rainfall events. In 
many cases high rainfall intensity led to lower yield, and lower rainfall intensity let to higher yield. Times of concentration and lag times were both of a few hours, suggesting some water reached the discharge in a relatively short time. Antecedent conditions bore little discernible relationship to discharge behaviour. The highest discharge peak was $9.8 \mathrm{~L} \mathrm{~s}^{-1}$ (approx. $5 \mathrm{~L} \mathrm{~s}^{-1} \mathrm{ha}^{-1}$ ), but in general yields from larger events were low whilst smaller events gave a higher yield. In general attenuation was high with an average greater than $90 \%$, the worst case being $64 \%$.

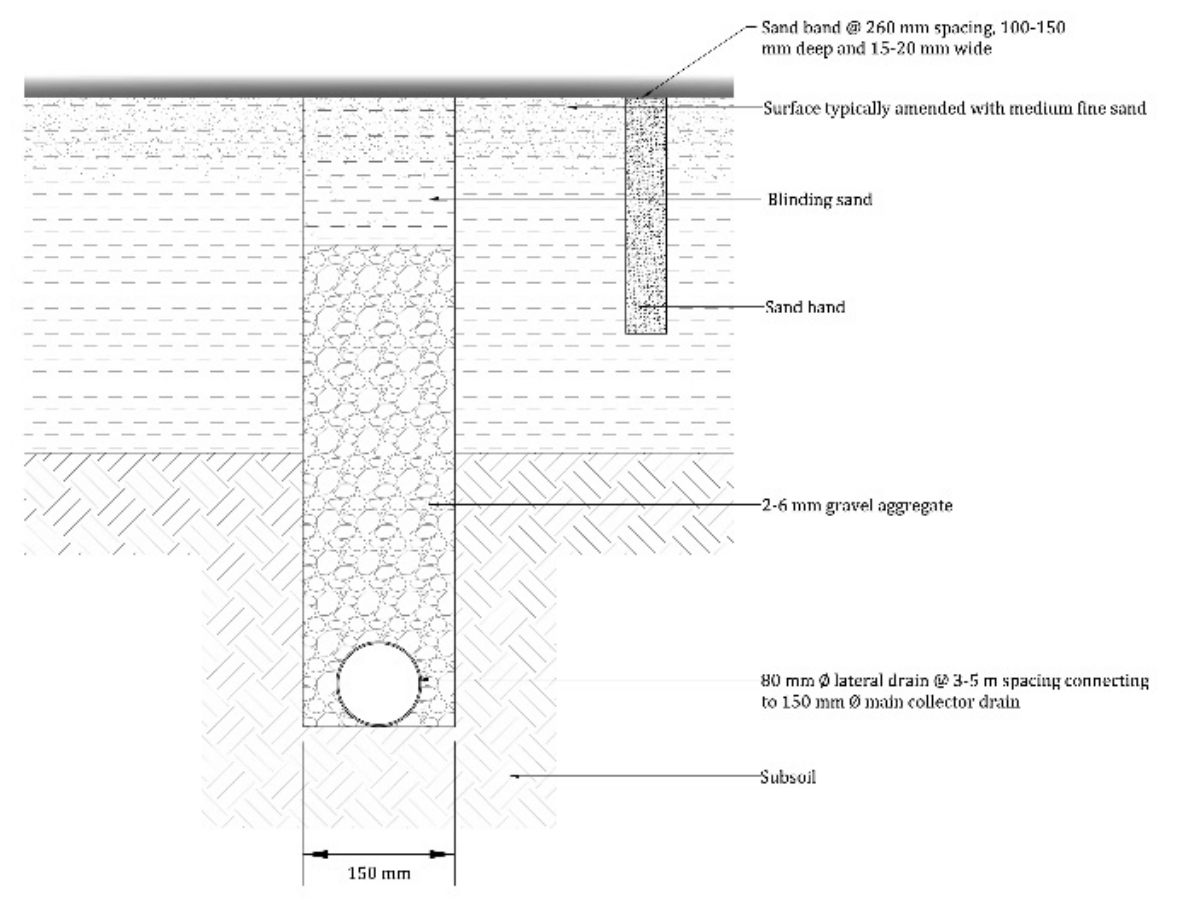

Figure 2. Typical cross section of drainage design elements.

The high yield event in Table 1 at Bicester from 21-22 January 2014 gave a total rainfall of $7.6 \mathrm{~mm}$ over a period of approximately four hours, at a peak rainfall intensity of $4 \mathrm{~mm} \mathrm{~h}^{-1}$ (Figure $3)$. The peak drainage outflow reached $6.9 \mathrm{~L} \mathrm{~s}^{-1}\left(4 \mathrm{~L} \mathrm{~s}^{-1} \mathrm{ha}^{-1}\right)$ approximately two hours after the peak rainfall. The pitch outflow continued for around seven hours. The volume out recorded was approximately $74 \%$ (yield) of the rainfall volume, with an attenuation of $64 \%$.

The low yield event in Table 1 at Bicester from 23-24 December 2013 gave a total rainfall of $199 \mathrm{~mm}$ over a period of approximately 18 hours, at a peak rainfall intensity of $53 \mathrm{~mm} \mathrm{~h}^{-1}$ (Figure 4). The peak drainage outflow reached $8.2 \mathrm{~L} \mathrm{~s}^{-1}\left(4.8 \mathrm{~L} \mathrm{~s}^{-1} \mathrm{ha}^{-1}\right)$ and was sustained for around 11 hours. In contrast to the event in Figure 3, the total volume out gave a yield of 14\% and an attenuation of $97 \%$. Whilst Figures 3 and 4 show very contrasting behaviour in terms of yield, the discharge flow rates are relatively high. Nonetheless, the data demonstrate a clear resistance to flow and reduction in discharge intensity relative to the storm. These higher flow rates are below the industry reported greenfield run-off rates of around 5-7 L s-1 ha-1.

\section{DISCUSSION}

The storms monitored in this study included events that equated to approximately 1 in 100 year events, and as such can be considered to represent worst case design events. It is clear that for both sites the drainage water volumes did not correspond to the surface rainfall water 
volumes generated. Indeed the data do suggest from the low yields measured during the very high intensity storms that some surface water was running off to local areas adjacent to the pitches, encouraged by the surface falls built into the pitch designs and in these specific cases there were open ditches adjacent to hedgerows that presumably intercepted the water. It is of course prudent to consider the wider site environs at any sport pitch development regarding the possible fate of any surface run off.

Table 1. Selected rainfall and discharge events.

\begin{tabular}{|c|c|c|c|c|c|c|c|}
\hline \multirow[b]{2}{*}{ Rainfall event } & \multicolumn{4}{|c|}{ Bicester } & \multicolumn{3}{|c|}{ Merchant Taylors } \\
\hline & $\begin{array}{c}20-21 \\
\text { Nov } \\
2013\end{array}$ & $\begin{array}{c}23-24 \\
\text { Dec } \\
2013\end{array}$ & $\begin{array}{c}21-22 \\
\text { Jan } \\
2014\end{array}$ & $\begin{array}{c}1-3 \\
\text { Mar } \\
2014\end{array}$ & $\begin{array}{c}20 \\
\text { Nov } \\
2013\end{array}$ & $\begin{array}{c}28 \\
\text { Nov } \\
2013\end{array}$ & $\begin{array}{c}29 \\
\text { Nov } \\
2013\end{array}$ \\
\hline $\begin{array}{l}\text { Antecedent precipitation (5 days) } \\
\text { (AP5, mm) }\end{array}$ & 1 & 59 & 7 & 21 & 26 & 56 & 60 \\
\hline Total rainfall (mm) & 4.2 & 199.0 & 7.6 & 12.1 & 14.1 & 36.6 & 5.1 \\
\hline Total rainfall volume $\left(\mathrm{m}^{3}\right)$ & 72 & 3410 & 131 & 207 & 351 & 916 & 127 \\
\hline Rainfall duration (h) & 1.8 & 18.0 & 3.8 & 11.8 & 7.0 & 6.6 & 1.8 \\
\hline Peak rainfall intensity $\left(\mathrm{mm} \mathrm{h}^{-1}\right)$ & 11.3 & 53.1 & 4.0 & 6.4 & 24.6 & 16.6 & 11.0 \\
\hline $\begin{array}{l}\text { Total volume discharged from pitch } \\
\text { drain }\left(\mathrm{m}^{3}\right)\end{array}$ & 9.6 & 462 & 98 & 129 & 3.4 & 115 & 5.7 \\
\hline Peak flow rate $\left(\mathrm{L} \mathrm{s}^{-1}\right)$ & 3.7 & 8.2 & 6.9 & 4.9 & 0.8 & 9.8 & 1.8 \\
\hline$\%$ yield & 13 & 14 & 74 & 62 & 1 & 13 & 5 \\
\hline Time of concentration $(\mathrm{h})$ & 1.1 & 2.4 & 3.9 & 1.2 & 2.3 & 4.4 & 2.2 \\
\hline Lag time (h) & 0.5 & 0.3 & 1.9 & 0.8 & 2.5 & 2.2 & 2.2 \\
\hline Discharge duration (h) & 2.2 & 21.5 & 7.3 & 11.9 & 3.5 & 11.4 & 11.4 \\
\hline Time to base flow (h) & 2.1 & 3.4 & 5.1 & 8.8 & 3 & 9 & 3 \\
\hline Antecedent dry period $(\mathrm{h})$ & 40 & 22 & 62 & 47 & 7 & 5 & 4 \\
\hline Attenuation of peak flow (\%) & 93 & 97 & 64 & 84 & 98 & 90 & 96 \\
\hline
\end{tabular}

The general trends in drainage discharge from the monitored sports pitches were also predicted to show greater discharges for higher intensity and longer rainfall events and wetter antecedent conditions. However, the influence of antecedent conditions was not observed to have the expected effect on the results. Whilst efforts were made to isolate events by considering the AP5 index value and looking for singular events wherever possible, without knowing the actual soil moisture conditions within the pitches, it is difficult to provide an accurate representation of the true antecedent conditions. Unfortunately, the site locations were active pitches such that there was limited invasive site investigation work that could be carried out.

The pitches monitored had no flow control (i.e. were uncontrolled discharge) and only in exceptional circumstances did the drainage outflow reach or exceed a flow rate that might be 
considered to require flow control. A simple flow control such as a hydro-break is relatively easy and low cost to install at the outfall chamber.

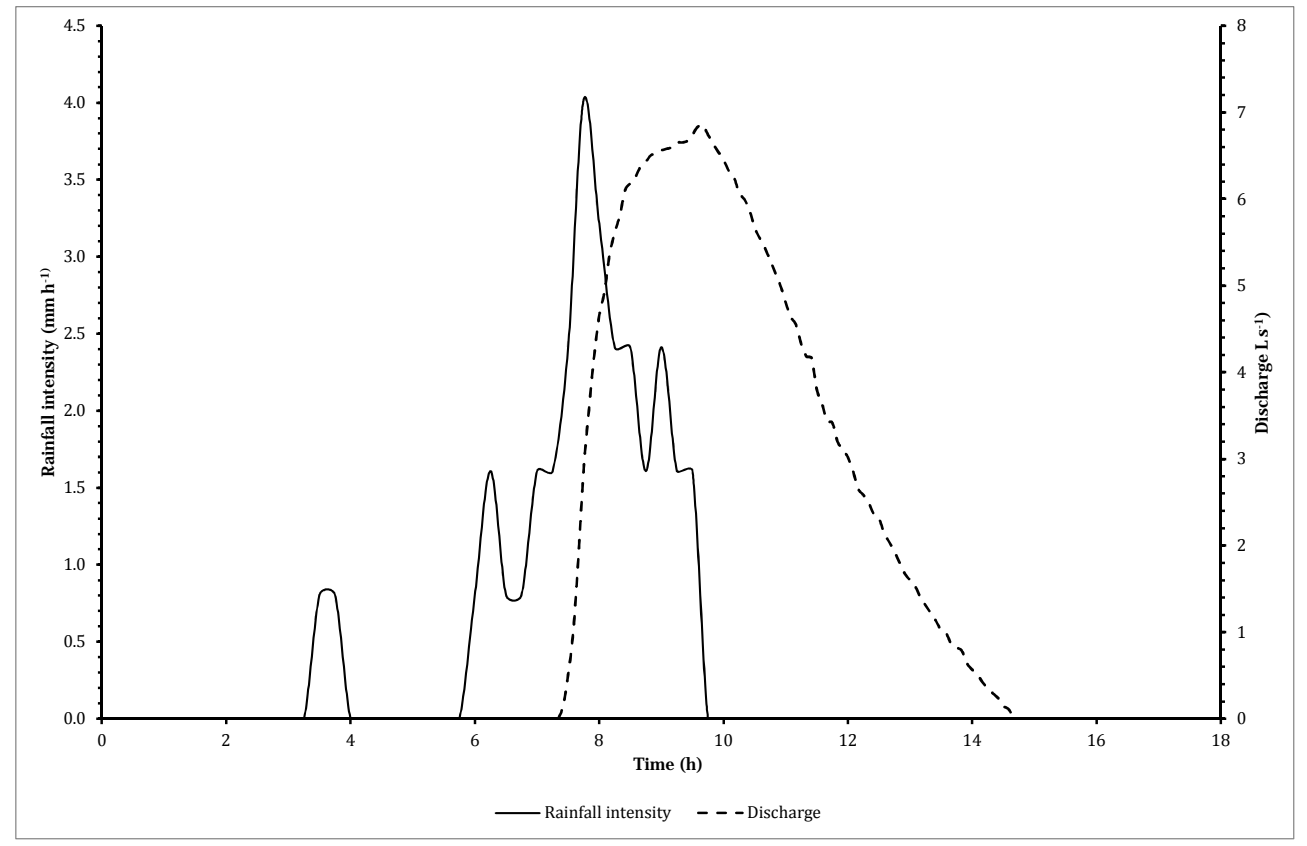

Figure 3. Example of a rainfall event which produced a high yield. In this case antecedent conditions were similar to the event. Note the similarity to the conceptual SuDs drainage diagram in Figure 1.

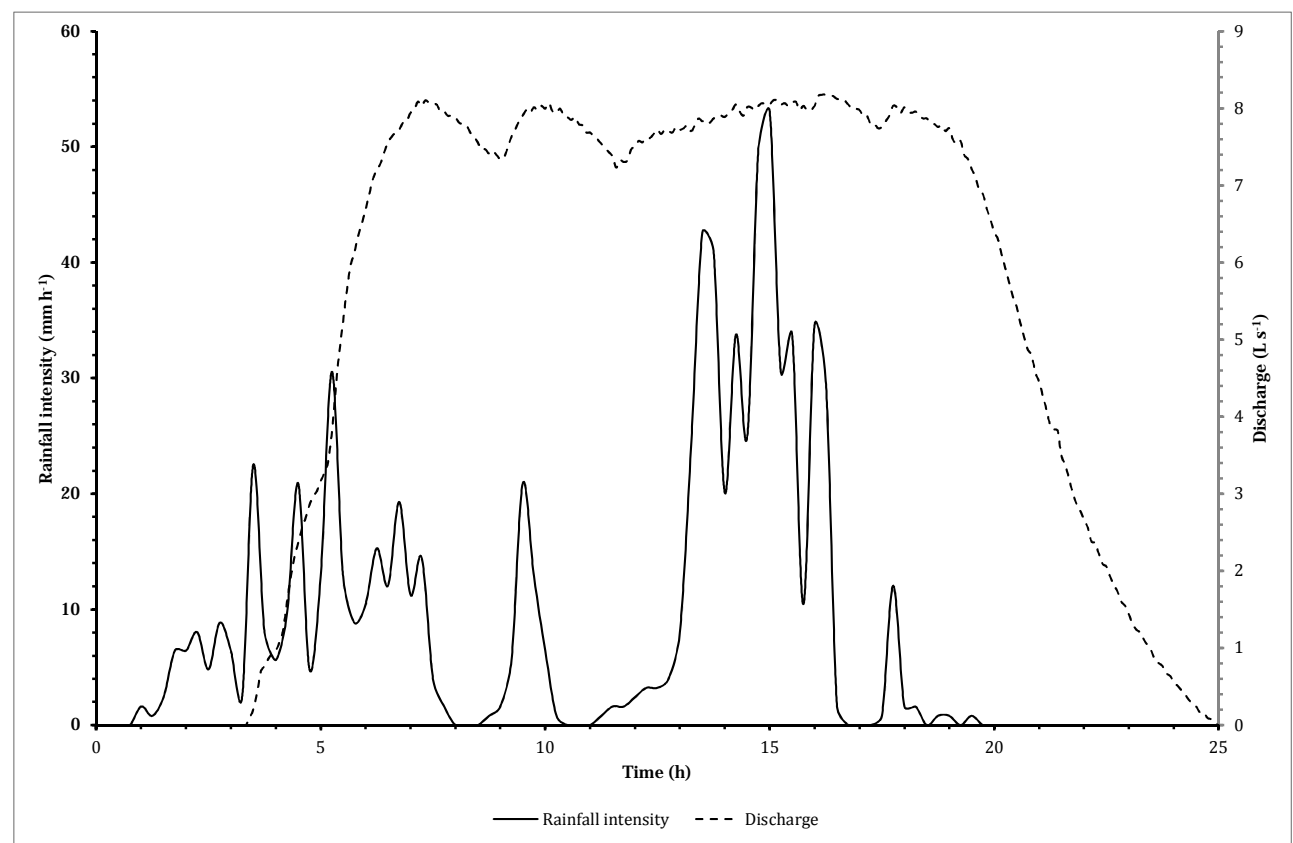

Figure 4. Example of a rainfall event which produced a low yield, showing a very large storm event. 


\section{CONCLUSIONS}

The field work here has demonstrated that natural turf pitch drainage designs can provide high attenuation of peak rainfall events and have a capacity for storage even without a flow control, similar to the requirements of SuDs based 'source control' designs required in new urban developments.

The field monitoring observations also suggest that in reality the drainage system behaviour is not as consistent or predictable as might be expected from assumptions made in design software (i.e. the water volume in is not equal to the volume out).

The overall finding of this study is that natural turf sports pitches can be harnessed as a sustainable drainage tool for integrated storm water management. In addition to their capacity to act as a method of 'source control' for surface rainfall water volumes that land on a pitch, there is potential capacity to permit the pitch to further enable the sustainable drainage of other local amenities such as the clubhouse/sports hall or other neighbouring pitches - if designed appropriately.

These findings support a need for both informing and updating current policy and practice regarding drainage design, to ensure that future designs are value engineered regarding discharge and run-off flood risk.

\section{ACKNOWLEDGMENTS}

The authors are very grateful for the support of Cherwell District Council, Merchant Taylors' School, The Sport and Play Construction Association, The Institute of Groundsmanship, Sport England, The Sports Turf Research Institute, and Agripower Ltd for aspects of funding, management, data collection and site access. The authors also thank Mike Smeeton, Mick Barker and James Hemmingway of Loughborough University for equipment technical and laboratory testing support and Jerry Anderson from Agripower Ltd for flume design.

\section{Literature cited}

Adams, W.A., and Gibbs, R.J. (1994). Design criteria and sports turf drainage installation. In Natural Turf for Sport and Amenity: Science and Practice, W.A. Adams and R.J. Gibbs (CAB International, Wallingford, UK), p.103.

Barros, V.R., Field, C.B., Dokken, D.J., Mastrandrea, M.D., Mach, K.J., Bilir, T.E., Chatterjee, M., Ebi, K.L., Estrada, Y.O., Genova, R.C., Girma, B., Kissel, E.S., Levy, A.N., MacCracken, S., Mastrandrea, P.R. and White, L.L., eds. (2014). Climate Change 2014: Impacts, Adaptation, and Vulnerability. Part B: Regional Aspects. Contribution of Working Group II to the Fifth Assessment Report of the Intergovernmental Panel on Climate Change (New York, USA: Cambridge University Press), pp. 688.

HR Wallingford (1981). Wallingford procedure for design and analysis of urban storm drainage (HR Wallingford, UK).

Mansell, M.G., (2003). Rural and Urban Hydrology. (Thomas Telford, London, UK), p.398.

Woods-Ballard, B., Kellagher, R., Martin, P., Jefferies, C., Bray, R., and Shaffer, P. eds. (2007). The SUDS Manual, Report C697 (London, UK: Construction Industry Research and Information Association). 